\title{
Doru POP \\ This is Not a Film You Are Watching. \\ Corneliu Porumboiu's Non-Cinematic Stylistics and the Visceral-Conceptual Cinema
}

\begin{abstract}
The hypothesis of this paper is that Corneliu Porumboiu, one of the most important Romanian filmmaker, who was extremely successful in international festivals, yet not so popular in public screenings at home, is looking for newer ways of cinematic expression, which go beyond box-office relevance. The second premise is that the Romanian contemporary filmmakers are moving towards a type of realism that is no longer connected with the philosophy of the New Wave or the Neorealist tradition, while entering into what can be called a non-cinematic cinema. Their search for a new cinematic expressions is taking them to a manifestation of cinema that does not take place onto the screen, but outside of the visible, beyond the immediate perception. This approach, identifiable in many other Romanian contemporary films (such is the case with Cristian Mungiu), takes in Corneliu Porumboiu's movies a conceptualized turn, a transformation of filmmaking itself. This is why the current discussion will be centered around the most recent three films of the Romanian director: Când se lasă seara peste București sau Metabolism (2013), Al doilea joc (2014) and Comoara (2015). The analysis of his most recent three films considers them as a coherent transformation of his artistic expression, which leads to a more personal cinema form, a visceral cinema. This paper is part of a more complex analysis of the process of decinematization and de-dramatization, which is taking place in recent Romanian cinema. As it is explicit in an experimental movie like Al doilea joc, we are witnessing a purposeful de-dramatization

\section{Doru POP}

Professor, Faculty of Theater and Film, Babeș-Bolyai University popdoru@gmail.com

EKPHRASIS, 2/2018

Cinema, Cognition and Art pp. 111-132 of cinema, which is part of a process of emptying the cinematic. The apparent emptiness in these films becomes an important element once interpreted as part of a search for an enigmatic sensation, for the palpable and the sensorial in a media that is only visual. As Roland Barthes used the term, we can understand Porumboiu's search as a quest for "visceral signs", for a hidden dimension of significations within cinematic representation. This term describes a type of cinema that supersedes the sensorial and the emotional (inherent to the cinematic) and circumscribes a profound search for the invisible nature of representations in cinema.
\end{abstract}

DOI:10.24193/ekphrasis.20.6

Published First Online: 2018/11/20
Keywords: Corneliu Porumboiu, non-cinematic, extra-cinematic, de-cinematization, conceptual cinema, visceral cinema. 
This study begins with an cinephile observation. Corneliu Porumboiu, who is one of the most important contemporary Romanian filmmaker, has been exploring new forms of cinematic styles, gradually transforming his art. In recent years, particularly since 2013, this remarkable Romanian director was working with cinema-making practices that are fundamentally non-cinematic. This shift from an acute realism to a more conceptualized cinema must be understood as part of a widespread tendency in recent Romanian films which has been followed by many filmmakers of this generation - including authors like Cristian Mungiu, Cristi Puiu or Radu Jude. Clearly Porumboiu explores a more radical option than some of his fellow cinema-makers, by abandoning the compelling realist representations of life and pursuing a conceptualized form of expression. In terms of cinematic narratives and of cinematographic practices this is an indication of a shift in the Romanian cinema-thinking.

We can undoubtedly identify two distinctive moments in the evolution of Porumboiu's cinema-making stylistics, clearly noticeable from the content of his productions and the modes of expression in each film. The first interval includes the director's early films (On the Wings of the Wine [Pe aripile vinului, 2002]; A Trip to the City [Călătorie la oraș, 2003]) and his two masterpieces (12:08 East of Bucharest [A fost sau n-a fost, 2006] and Police, Adjective [Polițist, adjectiv, 2009]) and his two masterpieces (12:08 East of Bucharest [A fost sau n-a fost, 2006] and Police, Adjective [Politist, adjectiv, 2009]) that received international acclaim. These films display a coherence not only because they have strong political messages and follow a similar, linear narrative construction, but also because they are created within the logic of realistic representation, of presenting Romanian society as it is. In the same time, they are critical commentaries about Romania's past and present, depicting contemporary society from an ironic point of view and offering a bitter-sweet perspective on the nature of human relationships in post-communist societies.

Stylistically and thematically speaking, the second stage in the evolution of Porumboiu's cinematic art begins in 2013 when, after four years of cinematic "silence", the Romanian director was able to make his third feature film. Without establishing any psychoanalytical connections, it becomes explicit that this long period of "artistic silence" ended with the finishing of a self-reflexive movie, relevantly sub-titled Metabolism (When Evening Falls on Bucharest or Metabolism [Când se lasă seara peste București sau Metabolism, 2013]), marked a radical transformation in this Romanian director's vision on cinema and his own artistic role. The following two movies - The Second Game (Al doilea joc, 2014) and The Treasure (Comoara, 2015) - indicate a continuation of this transformative direction, one that deepened his constant conceptual and even philosophical inclinations.

In all these three recent films the Romanian director addresses one of the most profound questions in cinema, the ontological nature of the cinematic, and is exploring the problematic changes of the substance of cinema in the new marketplace. 
By conceptualizing meaning-making practices in film and, more importantly, by internalizing the relationship between the medium itself and the effects on the author and the viewer, Porumboiu offers some of the most acute insights on what it means to be a movie director and about the internal mechanisms of cinema. In the following interpretation, this Romanian director is used as a case study for the alternative cinema-making practices happening in Romanian cinema, which is increasingly on the path of exploring the non-cinematic dimensions of this art.

\section{From the cinematic to the non-cinematic}

The predicament of cinema confronted with the changes in technology has been addressed by many film directors, and the contemporary Romanian film-makers were not impervious to the experiments taking place in the European art cinema, from the avant-garde films of Bunuel to post-media productions today. Many critics have attempted to explain the trends in recent Romanian cinema through the lens of the concept of postfilmic cinema, as developed by Garrett Stewart (2007). This is best illustrated the arguments presented by one of the most important cognitivist theoretician in Romanian film criticism, Mircea Deaca, who applied the concept of post-filmic when interpreting Cristi Puiu's movie Aurora (2010).

Before moving forwards, I must underline that my argument here is not based on the distinction between the "analogue" and the "digital", as claimed among others by Holly Willis (2005). When I am discussing the non-cinematic there is no difference between films made "traditionally" and those that are not created on celluloid. The fact that recent movies are made "digitally" or "analogous" does not make them more cinematic or non-cinematic - as many examples of digital films created by the Hollywood film industry today shows. Rather, as well pointed out by Deaca, who compellingly provides relevant examples from another investigative European director, like Béla Tarr, the discussion should be about the philosophy of the cinema as representation art.

In order to proceed with the arguments we must briefly return to the classical distinctions presented by Bordwell (5), who identified a separation between "classical cinema" (often identified with Hollywood cinema) and avant-garde modes of filmmaking, often describe as "art films" or "European cinema". To put it simply, we can trace a separation between the conventional and the non-conventional approaches to the cinematic practices. One of the most important conventions of the "classical paradigm", later to become one of the major conventions of global cinema, remains the use of the screen space. The way in which a director works with the visual space of the screen has a material impact on his movie being either cinematic or non-cinematic.

The most radical forms of contesting the conventional cinematic strategies were elaborated by the avant-garde film experiments, and it must be underlined that many of the representatives of surrealism and dadaism were part of the Romanian culture 
during the early XXth Century. As pointed out by Kaira Cabañas, in the analysis of the works of Isidore Isou and the Lettrist films (which included other authors like Lemaitre), the avant-garde artists dismissively refused the rules of "bourgeois" cinema. Isou (who was born in Botoșani, Romania as Ioan-Isidor Goldstein) was taking this most important battle of contesting the "obsolete" ways of making art into movies. In his searching for new expression forms, one of the solutions, explicitly showcased by the infamous "Chapter III" of the Traité de bave et d'éternité (Venom and Eternity, 1951), was the re-definition of cinema as a type of creation form that "does what it should not do". For the Lettrists this was the only way in which the medium could reinvent itself.

The contrasting classification is provided by Bordwell, who described classical cinema as an "excessively obvious cinema" (1985 1). This is a type of moviemaking designed for a viewing experience which keeps the spectator relatively safe emotionally and which does not provoke any complex thought functions. In this type of cinema everything must be explicit, simple and direct, all information that the viewer needs come from the screen. And in the stylistics of explicit cinema-making everything takes place onscreen, from the narratives that are constantly "orienting" the spectators and providing cues for interpretation, to the camera works that offer a logical and stable visual environment (Bordwell 50-6).

This explicit way of making movies and the assumption is that meaning must be created immediately, in the direct relationship between the images on screen and their impact on the soul of the viewer was radically rejected by Isidore Isou. In an expansion of the dadaist vision about art, he claimed the need for a cinema discrepant, that is a cinema where the meanings were never expected or easily anticipated. More importantly, for Isou the medium itself must be used against its own technical limitations. As Isou provocatively encouraged his fellow artists, there is a need to cultivate a spectator that could "eliminate the photo from cinema" (Isou quoted by Cabañas 14), reaching towards a a film without photography.

Of course Isou was following his own vision of "cinema as insolent art", yet it is in this very sense that we must consider Porumboiu's approach to filmmaking. His experimental form of expression is also going against the conventions of the medium by exploring how meaning is generated not only "on the screen", bu also how do the significations emerge by emptying the cinematic space of its intrinsic characteristics. Porumboiu opens the way for a "mysterious" dimension of cinema, one that cannot be discovered through following the canons of the classical cinema. By refusing rules of cinema, by reaching towards the very limits of the medium itself, he discovers the resources of the non-cinematic.

\section{From social criticism to a conceptual take on cinema-making}

Corneliu Porumboiu, who started his career as a movie-maker in the "shadow" of his internationally acclaimed and more vocal colleagues like Cristi Puiu, is 
nonetheless one of remarkable representatives of the new generation of directors that appeared after 2000. As I argued in another research, Porumboiu was born in 1975, and this eight years difference separating him from Puiu or Mungiu resulted in a noticeable distinction of his type of cinema practice (Pop 25). More so, unlike other fellow directors who constantly followed a single-themed style of cinema, Porumboiu's art kept evolving constantly. His early short films were based on a simple story - the failed emigration or failed institutions. While others, like Radu Jude, went on pursuing a political dimension in their films, Porumboiu reached beyond social criticism. After his first feature film, which was still determined by an overt criticism of the shortcomings of post-communist society like alcoholism, social hypocrisy or authority abuse, the director gradually made way in his narratives to a more profound exercise of philosophizing about cinema-making. As the social content of these early stories was diminished, another transformation was taking shape in Porumboiu's films, evolving from the dark humor and caricature-like depictions of society, to an exploration of psychological issues.

In this analysis I will explore Porumboiu's most recent three films, with the purpose of showing how each functions as a turning point in the evolution of his artistic expression. The central argument is that we can see how the director has created not only a particular cinema stylistics based on a conceptualized understanding of how movies are supposed to work, but also a visceral dimension, generated by his preoccupation for the ontology of film-making.

Many critics have noted what Jay Weissberg (2013) properly identified as the "cerebral" trend in Porumboiu's films, with Metabolism marking a turning point. As I would argue further, Porumboiu's approach is not purely cerebral, but rather visceral. Also, his art form can be linked to the conceptualist aesthetics which allows us to discuss these films by using another term, that of conceptual cinema. Placing this concept in the context already used by Luca Barattoni when describing the Italian postneorealists (Barattoni 2012), we can identify a "conceptual realism" in Porumboiu's recent works. This approach to film-making is founded on the ability of the director to use cinema for philosophical purposes, making way for another type of auctorial subjectivity, displaying an "invisible" dimension. Unlike essay films, where the voice of the artist is overwhelmingly present, in the conceptual approach cinema is used as an inquisitive tool, allowing complex visual experiments, that are exploring the very limits of the cinematic, without a direct intervention of the director in the process of filmic reception.

Another contention is that Porumboiu can no longer be described as a "realist" or a "naturalist" film-maker, not because he abandons the conventions of representing reality, but because he chooses a conceptual path. Reality is now a bi-product of ideas and concepts, and not he other way around. The three films which are the basis for a closer analysis, are interpreted from this central conceptualist principle - our brain is making the matter of the real, not the other way around. 
Without clearly indicating that his options have any roots in the conceptual art, or, for that matter in the conceptualist philosophies, Porumboiu's recent films indicate both these influences. On one hand, his recent works are similar to conceptual art. Just as Magritte or Duchamp used in their conceptual representations the famous pipe or urinal as real objects contradicting intellectually and textually the very nature of the representable, Porumboiu's approach uses the same negation of the essence of his own representations, the cinematic objects. The best example is Al doilea joc, where the director is talking to his father while watching together an old football match on a video-recorder, implicitly telling his spectators during the projection of his cinematic production: "This is not a movie". The same mechanism is put into action in Metabolism, where the cinematic nature of the movie being made while we are watching another movie is used as a reference for the absence of that very film. As the director and his actress are rehearsing the scene of a movie we will never see, what we actually presented onscreen becomes an expression of things selected by Porumboiu to remain outside the cinematic visible. This disruption at the level of understanding the nature of representation makes us witnesses of a film that is only a substitute. It is as if the director is telling us: this is not a film that you are looking at (or as a paraphrase to the notorious formula: Ceci n'est pas un film).

That is why one major manifestation of the conceptual approach to cinema is the constant return to questioning the nature of cinematic representation. A memorable example is Jean-Luc Godard and his decade long project Historie(s) du cinéma. This remains one of the most relevant and exhaustive cinematic efforts to conceptualize film-making within a filmic work, that is undertaking a critical view of the craft while making a movie. Here Metabolism is the closest example for how conceptualization of the cinematic operates. The film title itself provides a multi-layered metaphor for moviegoing practices - "When Evening Falls on Bucharest" is simultaneously an indication of the "twilight" of cinema, a purposeful reference how watching movies takes place in the dark, and an implicit hint to the shadow-casting nature of moviemaking, the illusory character of any film. And, just like the conceptual artist who are pushing the limits of the representable beyond the canons, we see Porumboiu pushing the limits of the cinematic beyond the traditional understanding of the medium itself.

The conceptual cinema is also philosophical, in the sense that entails a constant meditation on the role and human condition of the author, not only a reflection on the mechanics of his craft or the characteristics of the medium itself. This is a type of movie making that is no longer preoccupied exclusively with the representation and the realism of the represented, but is oriented towards understanding the nature of reality and questioning the limitations of the representable. This conceptual quality is also underscored by its reduced social and political contextualization, the characters and their personal stories provide almost no external references, and there are no ideological meaning attached to their condition. 
Last, but not least, by asking what is the essence of the cinematic (at a conceptual level), Porumboiu takes the path of an introverted view, by looking inside his own presence in the representable. As I will argue in the following of this interpretation, the visceral sign is a very useful a term for us to understand this process. Introduced by the French semiologist Roland Barthes (29), who created it when dealing with the analysis of what he identified as difficult signs, or duplicitous signs, we can apply it in within the structures of cinematic meaning production.

\section{Inside the metabolic system of cinema}

Când se lasă seara peste București sau Metabolism was early on considered by many critics as a "self-reflexive" movie. Naturally, as Porumboiu himself acknowledged in many interviews about Metabolism, this is a film dealing with the nature of his own art and, particularly, a meditation on his own condition and evolution as film director (Porumboiu 2013). Yet the self-representation, which is obvious by linking the film with an autobiographical dimension, is only the first level of this film about a Romanian director named Paul, played by Bogdan Dumitrache, who shares the same dilemmas that Porumboiu has. His pondering about the nature of cinema goes beyond the simple rumination about what it means to be a film maker, or about the nostalgia for celluloid in an age of digital cinema.

Metabolism is apparently an unremarkable movie, empty of actions, dominated by over the shoulder frames, with redundant and fixed two shots and with dialogues taking place in austere mise-en-scènes. The first impression is that of a film purposefully emptied of complex cinematographic elements, with spaces that are reduced to a minimum of elements. Yet, at a closer look, the film displays more that the typical "minimalism", disclosing a conceptual turn in Porumboiu's understanding of the cinematic art. It makes clear the opening of his craft towards a more complex direction, one in which the simple self-reflexive contemplation or the minimalist references are overpassed. Inconspicuously and constantly all the scenes of this movie revolve around discussing the nature of cinema - be it directing, location scouting, acting, creating dialogues, or camera movement. This accumulation makes he entire film to be an extensive conceptualization of the nature of cinema, a meditation on the ontology of filmmaking. A brief overview of the sequence buildup in Metabolism shows how each piece of the film is centered around a concept and not an action. In the end, the entire movie becomes a glossary of the specific elements of cinema, an exploration of the metabolism of filmmaking.

Following a day in the life of a movie director, who appears to be loquacious and inquisitive, even determined in his efforts to tell his story, the film discloses a weakling man. Dominated by his actress and his woman producer, this alter ego of the director himself also suffers from an acute stomach pain. This psychological indeterminacy is paralleled by the visual structure of the movie. The spectator is presented with an apparently simplistic setup, a chain of story divided into seventeen sequences, with 
an intermediary intervention. Alternating longer shots and short ones, the director reveals more than a rhythmic manner of editing, creating an access to the unconscious of the main hero. His camera movement decisions are also revelatory - the first part is dominated by immobility while the second part uses excessive camera movements. We must note also the major role is played by the color transformations, the shift from warm to cold tones is designed to mimic the evolution of the storyline. Technically speaking there are seventeen sequences, and for the purpose of this analysis each sequence is enumerated and briefly described, with an account of the length of each scene between cuts.

I. Car-drive at night, with two characters surrounded by darkness. Topics discussed: the nature of cinema. Length: 6 minutes. II. Paul alone in the white kitchen, has a cell phone discussion with Magda, the producer. Topics: Paul is in pain he cannot go to filming, references to film production. Length: 4 minutes. III. The rehearsal of a scene with his actress and mistress, Alina. Topics: dialogues and cinematic spaces, what is expressive in film-making, bodies, mise-en-scène. Length: 8 minutes. IV. A closed door, covers a sex scene. Topics: the relationship between sound and image, silence in films. Length: 2 minutes. V. Chinese restaurant dinner, built as a two shot. Topic: becoming an actor, the nature of content production and mediation, form and content in art. Length: 9 minutes. VI. Reverse shot in the car during the day, with Paul and Alina. Topics: international cinema, ethnicity, identity. Length: 6 minutes. VII. Paul and Alina meet with the producer, Magda. Topics: practical dimensions of cinema-making, contracts, bills. Length: 6 minutes. VIII. Paul is alone in the car. Topic: silence and simple set-up. Length: 2 minutes. IX. Back to rehearsals. Topics: rehearsing and performing, acting in real time, the nature of reality. Length: 8 minutes. X. Post coitum scene, with the camera following the actress, then the director. Topic: the film within film. Length: 11 minutes. XI. Dinner, starting with a two shot, then a three shot. Topics: screenwriting, budgeting, other perspectives on cinema, director's competition, cinema history. Length: 8 minutes. XII. Outside scene, Paul and Alina are smoking while waiting for a cab. Topics: the uncertainty of playing and directing, the difference between theater and cinema. Length: 4 minutes. XIII. The director starts watching parts of his movie on a projector, a single camera pan with him. Topic: solitude of the creator. Length: 2 minutes. XIV. Opens as hotel lobby scene, with camera panning almost 360 degrees. Topic: real time interaction. Length: 1 minute. XV. Meeting with the actress at the bar, camera is fixed. Topics: the social dimension of a movie. Length: 2 minutes. Intermediate sequence with the endoscopic evaluation, overhearing the comments of the doctor and the producer. Length: 2 minutes; XVI. Final discussions about the endoscopy. Topics: the doubtable the nature of representation, the importance of focusing on the subject of filming. Length: 4 minutes. XVII. Taking place within the same scene, but with the changing of characters. The make-up artist and the actress enter the trailer. Topics: the role of make-up, understanding the purpose of cinema. Length: 4 minutes. 
This formal construction allows us to observe how Metabolism deals with multiple levels of meaning formation in filmmaking, investigating almost all the limitations of the cinematic art, from the ontological nature of the celluloid, to the intellectual strife of the film director, from the narrative structure development to the relationship with the actors and other directors. In this sense, this 2013 movie announces Porumboiu's transformation, from an extrinsic inquiry, to an interrogation of nature of cinema, the ontology of the medium and the understanding of meaning production in film practice. Everything in this movie, even the dialogues, are transformed into conceptual exchanges of ideas - each shot functioning as an illustration of a cinematic concept.

There are remarkable scenes in which the movie deals with the nature of filmic representation within the cinematic structure. We have Paul discussing with his actress the limitations of the film strip, pondering about the fact that one cannot film more than 11 minutes at once - and by consequence none of the scenes are longer than that. Next the director in Metabolism muses about the fact that films are going to be different in a couple of decades, and the ontological nature of cinema is going to change. This limitation generates a mode of thinking through cinema and, through the words of Paul, it is Porumboiu who tells his viewers: "This is how I think". Later the movie director is seen watching his own movie, and while we are watching him in darkness of his living-room this movie within movie is never displayed. As we do not have enough visual data, we are compelled to see it in our minds.

The most important moment in Metabolism is what I called the "intermedial" sequence. Here we see an endoscopic footage of the entrails of a human being, while we listen to the offscreen discussions between the doctor and the producer. Paul, the director of a movie with difficulties in the process of production is having troubles with the reality around him. This narrative setting allows Porumboiu to explore, through his characters, not only the inner mechanism of moviemaking, which is in a symbolic way the "metabolism of cinema", but also the internal nature of moviemaking. Also noteworthy is the fact that Porumboiu makes an intertextual reference when naming his main character Paul, same name as the screenwriter in Godard's Le Mépris. While the premise of the two movies is explicitly similar, just as Godard contemplated autobiographically the nature of his craft, Porumboiu descends into a complex exploration of the visceral dimension of film-making.

\section{Visceral signs, visceral cinema}

In order to understand the way this type of cinema works, we need to make a brief parenthetical discussion about the functioning of the cinematic signs. Although most of the film critics follow the traditional, structuralist view which discusses the nature of the cinematic sign within the classical paradigm supported by Christian Metz, that is cinema has no process of signification outside its predetermined values (Metz 1974). The objects that we see in movies are already coded with significations. This apparent 
technological transparence, as noted by Barthes (1972), is actually an indirect source of hiding meanings, not of making them clear. Obviously in films, as in other visual arts, the access to the visible does not provides us with the explanations necessary to understand the significations.

This is why viscerality, in the words of the French semiologist, represents that dimension of the visual signs which is "revealing an internal, hidden facet" (Barthes 26). Here the need to clarify that the use of visceral must be understood as different from the concept of "carnal cinema", as proposed by Bordwell (2000). The distinction is important, since visceral cinema is not synonymous with carnal movies, although in some contexts it might be perceived as a manifestation of the corporeal film. This is the case with Metabolism, since the movie begins with the director stating forcefully: "Tomorrow I will shoot a nude scene". This allows us to plunge in the middle of a very intense discussion between Paul and his actress/ lover about the beauty of the woman's body, the ugliness of the male body and the fact that the penis is a body part that "ruins the harmony". This in turn leads to the actress refusing to "act naked in a sequence that is not justified", yet it does not prevent her from engaging in a sexual affair with the director, while having her own partner at home.

Robert Furze extensively explains the other uses of cinematic visceral sign, used as a way of trying to hide the intentional presence of the director (Furze 2015 12-13) and cover the filmmaking strategies by emotional intensity. Here the visceral is not opposing the intellectual, it is a methods of allowing the presence of the artist/ creator to be diminished and the viewer to immerse into the subjective experience. In this case Porumboiu's subjective representation of the inner world of the director, hides his own presence. Thus visceral meanings are manifested in such a way that, even if created by the mind of the director, they are beyond the control of the conscious mind. The visceral is taking over reason and intelligence, offering the viewers an alternative access to a secret dimension of meanings.

Once more Metabolism provides the relevant illustration for this transfer of meanings, from the conceptual to the visceral. During several scenes there are intense discussions between the director and the actress on how they should shoot a scene, only to fail in doing it properly (within the movie). This rehearsed part of the fiction then becomes a scene in the movie itself, only with reversed roles. In this way Porumboiu uses the visceral dimension of cinema as simultaneously a personal experience, and a mediated (secondary expression) representation. The movie within the movie transforms the conceptual into the visceral. The same mechanism is used in the scenes where the director and his actress are eating. One is at a Chinese restaurant and the other takes place in the presence of another director (played by Alexandru Papadopol). In both situations the discussions (the conceptual level) are turned into visceral meanings. For example, in Paul's monologue about Oriental cooking and cuisine - which is extremely similar to the arguments provided by Barthes in his comments about Japan (1983 3-4) - the director argues that the external 
tools we use to eat are, in turn, creating cultural habits. The entire discussion, which seems tedious and even erroneous (since in fact there is fried chicken in the Oriental cuisine), punctuates the nature of reality and provides us with a visceral access to the relationship between the man and the woman.

Further more, although Porumboiu was always making movies that were close to his environment - with both his feature films made before 2013 taking place in his hometown of Vaslui - his explorations of his personal life became intense. In an interview, when asked about the motivation for creating $\mathrm{Al}$ doilea joc, the director answered that it was "something extremely visceral when I first saw the match... I couldn't make any sense of it because of the snow and I wanted to understand myself" (Porumboiu interview 2014).

This is visceral nature of Porumboiu's cinema, using film to understand things that are otherwise impossible to understand. There are many ways in which the visceral dimension is used in cinema. There are several visceral genres, movies that create an empathic relationship between what we see on screen and our reactions. Just like the ulcer of the director in Metabolism is a reaction to external stimuli, our bodies react to the images we expose ourselves to. Slasher films and other violent sub-genres are described as part of the visceral trends in filmmaking, they elicit immediate reactions from the viewers.

In cinema theory viscerality has long been a subject for philosophical and practical evaluation. Although the impact of cinema on the brain of the viewer has been extensively researched in film theory, since Münsterberg and Arnheim, many specialists claim that the experience we have with the moving images is fundamentally psychological. Our minds react to the actions on screen and by seeing others suffer or be happy we generates similar sensations in our mind.

Yet, as many cognitive psychologists have pointed out, the direct perception of reality is not the only way we understand the world and our place in it. One of the most relevant concepts is that of the "visceral perception" (Ádám 1998), which allows us to take into account what happens within the body when a sensorial experience takes place. Actually the visual stimuli are transformed into bodily activities, not only at the level of the perceptive system or as psychological reactions, but in the very carnal. When exposed to images we receive not only cerebral information, but also visceral information at a level that we most of the times are not aware of. In fact the external movements of the actors on scene, the images projected on screen or the words we hear are transformed into internal movements of our bodies. The idea of visceral cinema integrates the fact that what takes place on the screen is transformed into a visceral understanding of what is beyond the visible.

Thus a major part of our cinematic experience takes place within the visceral processes - the disgust, sympathy or attachment we experience towards the action or actors in a movie is projected beyond the screen, beyond the mind of the viewer. In any case, this is a cinema that is not happening only on screen. The movie does not take 
place only in our minds, it also takes its impact on our guts. Those who have cried at the movies know this process first hand, since watching a film (just like reading a book) has an emotional and sentimental result in our bodies. Movies make us sad, happy, nervous or fearful - they basically are visual machines the move us.

Such visceral capacities of cinema as a visual medium are explored (and exploited) in the practical visceral genres: mostly erotica or pornography, in violent movies, revenge films and so on. There is no place here for a larger discussion on the topic of visceral manifestation in cinema, enough said that any form of violence, of direct use of physical aggression we witness on screen is turned into a visceral experience. Such movies can "move us" even without the help of images, for example through the manipulation of sound design and of special effects.

More important is the process described by neuroscience as "interoception" (Cameron 2002), what describes the overall activities that take place in our body as a comples sensory-perceptual system. Basically our entire body processes and transmits signals and even awareness, not only our brains. Jeffrey Zacks (2015), who was among the first scientists who used fMRI equipment in order to provide explanations for how movies impact our brains has shown how ideomotor actions (4) are stimulated. On one hand we must start with the idea that our brains have evolved in a non-cinematic environment, one in which the ability to mimic the actions of other humans was fundamental for survival. The consequences are even more important, since our brains are built as somatosensory machines - which means that what we see with our eyes is decoded by our brains and is turned into bodily reactions - they constantly incorporate what we experience at the perceptual level. This is the scientific foundation for the visceral cinema - based on this mechanism of translation - the brains transforms emotions into reactions, or as Greg Smith has properly described it, movies simply put us into specific moods (Smith 41).

Another definition of the visceral is phenomenological, as Merleau-Ponty argued, there is a phenomenological connection between the flesh and the act of seeing (151155). In his influential book The Visible and the Invisible, the French author brings forward the undeniable fact that the apparent and constant visibility of any visual medium is actually preventing sometimes our immersive capabilities. By viewing a film while knowing that it is a film, the viewer remains at a superficial level of contact with the story, the figures of actors or the changing of actions due to the barriers of consciousness. Yet the role of visual representations is never direct, it does not work simply by creating connections between the showed, the visible, and the viewer, but rather to bringing forward the invisible, that which is absent, which take place outside the perceptible, since it happens in the flesh.

So, even though there is nothing "organic" or "natural" about cinema, and its material manifestation (the celluloid) is never in contact with the us, thus providing a non-tactile, and non-material experience, it has a deep visceral effect. 


\section{The non-cinematic and the intermedial}

With $\mathrm{Al}$ doilea joc Porumboiu challenges in an even more radical way our understanding of the nature of the cinematic. Using archival material - a soccer match from communist Romania - the director once again appears to make a selfreflexive film. The film begins with an explicitly personal inter-title stating that, when the director was 7-8 years old, somebody called him on the phone and told him that, if he did not persuade his father from giving up being a referee, his father will "return home in a coffin". For the rest of the almost 100 minutes the spectator will be presented only with the images from an old videotape of a football match, overlapped by the voices of two men who are re-watching the game, while discussing apparently unimportant things. We soon understand that the two are father and son - Adrian Porumboiu, the father of Corneliu Porumboiu, and the director himself. Porumboiu, the father, was a football referee during communism, and then later he owned his own soccer team in their hometown of Vaslui. His attitude is somehow detached and appears to be unaware of the fact that the son is recording this discussion. The two teams playing are Dinamo and Steaua, the most important teams in Romanian at that time. The match is taking place in December 1988 and was refereed by Adrian Porumboiu, himself, at that time an important figure in the Romanian sports. This is the external context which allows father and son to talk about the past while making small-talk observations about the present.

Is there a more complex level of meaning in Al doilea joc, or is it just another "boring Romanian movie", filled with "senseless pictures" and monotonous to exhausting (Totok 2014). Indeed we must ask what is the point of making a movie which shows for an hour and a half an old soccer game from December 1988 (just one year before the Romanian Revolution), with blurred television pictures commented by a father and a son? Is this cinema-making anymore? And, more importantly, how can such an approach be relevant for the way in which the cinematic meanings are generated?

On a more profound level, $A l$ doilea joc must be seen as an intermedial product, as defined by Lars Elleström (2010), who compellingly argued in his book about media borders that the relationship between intermediality and multimodality is fundamental for our understanding of the interplay between arts. The combination of any recent media - like mobile phone pictures or other digital screen recordings with old media (as analog cinema is today) can become relevant when discussed as a meaning making tool going beyond the particular mediums of expression.

We must start by the questioning of this movie by trying to explain the use of "found footage" material. The practice of integrating footage from home videos in movies is not a novelty in cinema-making and, more importantly, after Soderbergh's Sex, lies, and videotape (1989), the technique itself became an integral part of mainstream Hollywood productions practices. While the "classical" found footage narratives are basically fictional stories presented as if they were real recordings - as in the case of Blair Witch Project - other contemporary productions (Cloverfield, 2008) are 
integrating fake television footage, or live recordings, as a path to generate cinematic authenticity. Thus the first level of meaning when a director is using found footage must be linked with the search for the authentic. What can be more "real" than the real time recordings?

In Porumboiu's film, the television footage projected on the cinema screen is already an intermedial manifestation. It is not a television program (that is visualized in the televised mode), as it is no longer "live", but a video-recording. It soon becomes clear that this is a transformed version of reality, since the live presentation (the match taking place during communism) is not real in its border crossing nature. More importantly, since the cameramen at that time were under the political surveillance of the communist regime, were not showing what went on the field. In fact the television operators moved the camera over the spectators in order to cover any negative attitudes of the players during the match. This hidden and edited nature of "the Real" becomes a very relevant part of the discussion between the two Porumboiu men. Their "realities" are completely different - while the son reminisces about his fears and emotional discomfort, his father considers the entire game to be irrelevant. "Nobody watches things from the past", he tells his sone, these are irrelevant events. And football, just like cinema or other art forms, Porumboiu Sr. claims, have their moments than they disappear.

At first glance this null match, without any clear finality and no apparent impact, is symbolically relevant. It reveals the murky nature of society during communism and is an exploration of intimate relationships during a time of total control in the public lives of all Romanian citizens. Beginning with the aguish of a young boy and his perspective on reality which is different from his father's - actually the director tells his parent during this dialogue that when he saw the game he was filled with fear. In a detached manner his father asks him: "How old were you?", "I was 13", the director replies, and father simply gasps. Their reality and their reading of that reality is clearly different - during the game the son sees the players fighting, while the father does not; the son claims that the match is beautiful, the father declaring it irrelevant.

The discussion about the irrelevant nature of the soccer match, and by consequence, of any content production has to do with the qualities of the cinema. Using the term used by Bernard (2009) to describe de role of the archival materials, the footage is there exactly to allow us to understand the ephemeral nature of representations (23). Many images and, in fact, many materials from the past in television were created to be shown only once, never to be re-watched again. This football game footage, which at the moment of its original broadcast was viewed in a real time, had a deep emotional charge and, through its instantaneous nature, personally marked the people watching it.

As pointed out by Adrian Porumboiu, for the father who is simultaneously an "actor" (as the referee of the match), a commentator and a viewer the archive footage, 
the whole match is unimportant. For him this is a non-event and he suggests that the son should have picked a more "memorable" television broadcast, like the Cup Finals from 1988, in which Steaua left the stadium considering that their goals was unfairly annulled by the official referees. By contesting the relevance of the material, the director brings his viewers into a frame of representation that contests very the nature of the representable. Without discussing extensively these aspects, the question here is what makes any visual product relevant, specially if the images are unclear and washed away?

The use of unclear pictures, or as suggestively defined by Jihoon Kim (2016), when referring to Hito Steyerl's films, the "politics of poor image", compels the viewers to a re-configuration of the qualities of the media that carries the message. All the three productions discussed here share this common element. Metabolism, Al doilea joc and Comoara are all movies that deal, in a different manner, with the limits of their medium and make use of other media in order to convey meaning. In fact Porumboiu's use of different non-cinematic media in the medium of film allows the exploration of the limits of the aesthetic of cinema as a representational tool. By including an endoscopic video recording inside Metabolism or by using an antiquated television footage in $\mathrm{Al}$ doilea joc, the director is in fact questioning the mediality of his craft. This the crossover from one medium to another is also present in Comoara, where the ultrasound recordings are made an integral part of the visual field of the spectator. Through the constant intervention of other media, from television to digital screens, from endoscopic recordings to ultrasound scans Porumboiu is searching for a "transmedial" resource, one that would allow him to transcend the limitations of his own medium.

I would argue in the following that we need another definition, one that would allow us to interpret Porumboiu's approach and other Romanian contemporary productions. In order to have a common term, I propose the concept of extramediality - which is different from intermediality and transmediality. Just as the director of $A l$ doilea joc is questioning the meaning-making resources of cinema and uses tools that are outside the medium, the significations traverse the boundaries of all the media used in this particular film - cinema, television, scanners, cell phones - they all show a limited capacity of meaning making.

\section{Extramediality and the borders of the cinematic}

My understanding of extramedial representation derives from the Derridean concept of parergon, as presented in his classical work The Truth in Painting. To simplify the argument, I would define extramediality as a mental, visual and conceptual plane, generated wherever the invisible dimension of representation is projected. This exteriority of the visible, the hidden nature of the representable within cinema is also a problematic issue in film theory. The dialectic relationship between the visible and invisible, or, as Noël Burch puts it, the complex dialectics of an art which is generated 
in-between the presence and absence on screen (Burch 1981) is not easily dealt with. Cinema is about the shown and the unseen, about the elements that are present in the visual field and those that are only suggested or even absent - this dynamics is fundamental for our understanding of how cinema works. Or, as Jaques Rivette (1961) pointed out in his seminal article about abjection in film-making, creating a movie is not just about deciding what to show, more importantly, it is about what not to present the viewers.

Cinema, and for that matter any art form based on visual representation, is only a flat image limited spatially by its frame and a clearly delimited form generated by its technical limitations (Aumont 11-12). This material nature of the visible, be it limited by the borders of the tableau, or the end of the projection canvas and the camera format are, as the French film aestheticians suggest, generating the specificity of the medium. Any movie representations, at least in the canonic cinema, happens within the visible field. Thus the cinematic meanings always takes place in the visible, that is onscreen.

In the theory and the practice of cinema we can identify four basic visual spaces where the narrative can take place: frame, extra-frame, field, extra-field - or using the French terms as defined by Gauthier (1982): cadre, hors-cadre, champ, hors-champ. The represented space in cinema is, in fact, conditioned by the relationship between screen (frame/ cadre), which delineates the field of vision, and the field of imagination. The cinematic frame, which contains the cinematic image, it is a rectangular shape, with fixed boundaries within the theater where projection takes place. When used as a positive space, the frame keeps actions and actors onscreen, in order to maintain the order of meanings. This restricted nature of the cinematic space is considered by classical film theorists as an integral part of what makes movie-making a "real art", through composition and aesthetic arrangement of space (Arnheim 17).

Yet the essence of cinema, as noted by early cinema-makers like Sergei Eisenstein (16), is generated beyond screen limits, in the mysterious space that is not simply the frame. We don't perceive the cinematic visual space as closed since any spectator, while watching a movie, has an experience that is not limited by these artificial boundaries. This spatial reality can be defined as "kadr", different from "frame", since it contains more than the simple images made available on the screen, more than what was cut by the framing. Through the process of mise en cadre (the putting into a frame), as the Russian director and film theoretician explains, there is an act of montage, by which the film-maker makes reasoned decisions about what is kept inside and what is left outside the visible representation. In the same time the spectator makes an inverse process, sometimes unconscious, of reconstructing reality from outside the frame.

Thus the "outside" of the frame, which is the invisible cinematic content, becomes more important that what is actually seen. Sometimes the directors are using camera movements to show the spectator previously unseen spaces. Even so, this would in turn leave other parts of the scene invisible. This makes the offscreen a constant and 
important part of cinematic narratives - as Noël Burch describes it in the seminal work about film practices, the "off" space can be outside the four edges of the frame (left-right, up-down), behind the scene or behind the camera.

Many European directors have explored the aesthetic and the resources of decadrage - that is exploring the limits of using what is outside the frame. While classical films treat the outside of the frame, the "off" space (imaginary or real) as negative - a character stepping out of the frame is going to die, or a monstrous action that takes place outside of our gaze - in European cinema this is a common technique, and even a trademark of the New Wave directors. Maybe the best example is in 4 months, 3 weeks and 2 days, where Mungiu brilliantly places offscreen the atrocity of the rape, while keeping the act itself in the narrative field (champ). The same technique is illustrated brilliantly by Porumboiu in Metabolism - he refuses his viewers the direct access to the sex scene, which is nonetheless taking place within the field of vision, that is in the frame, but outside the visible. And, as pointed out before, the whole act happens within the minds of the spectators, leaving a bodily trace.

Yet when we are talking about extra-mediality we are not refering to such classical techniques. Not because they are now part of the canonical cinematic means of expression, but because they are not really "outside". The true exploration of an extramedial experience happens in Metabolism, in the scene where Alina, the actress/ lover of the director, takes a phone call and exits both the visible and audible fields. She is now using another medium, which is totally refused to the cinema viewer, and through visceral connections, is made available. Through the cinematic image we have no access to reality, our only possibility is to reconstruct that reality by another medium. This is in fact an ontological dimension, which affects the nature of the cinematic experience.

Another dimension of extramediality is used in Al doilea joc - by using the apparent explicit images of a medium (in this case the television), it only makes more confuse and unexplainable the reality.

Porumboiu takes the exploration of the off-screen experience to another level, one that can be described as extra-cinematic. In Al doilea joc the limits of the cinematic representation are signalled by the use of a multimodal non-cinematic tool: a video tape recording a television program. Thus the screen of one medium is blocking our access to the representational field of another and the significations are exported from one medium to another. The camera view forbids our access "behind" the visible, while the recorded show is synchronized with another medium, the sound generated by the microphone. The sensation of presence created by the sound is broken by the visual representation of absence produced by the off-screen cinematic dimension. The father and the son are never showed, and we only see the ghostlike presence of the father as a young referee in the game. Here again it becomes more important what is not present. The apparent banality of the dialogues between father and son actually hides the profound and complex realities of communist Romania. While the two 
are discussing about the communist Secret Police (Securitate), and the relationships between the team of the military (Steaua) and the team of the Militia (Dinamo) we are taken into a reality that is in fact cloaked. Once more, the extra-cinematic can be identified as being more than what we see through the medium itself. The political schemings and interpersonal dealings, that were taking place "behind the scene" during Ceaușescu's regime are only one part of this unseen nature of reality. In fact the medium itself is a tool of hiding the truth, since the "live" television transmission that was broadcasted at that time was "doctored". An important player appears on the field with a head bandage, yet the spectators never saw the actual incident; any conflicts between the two teams on the field are hidden by the technical intervention of the cameramen who move the frame in a neutral portion of the visual field as soon as any aggressive gestures happen.

Once again, the ontological nature of both media is contradicted, and this negation constitutes the principle of extra-cinematic (or extra-televisual). Since tele-vision means viewing from a distance, the Romanian director uses the "distance" of the medium to generate intimacy, both domestic and psychological. And by putting his discussions with his own father behind the "curtain" of the soccer match Porumboiu generates a contradiction of the cinematic medium. The movie contains long minutes of silence, with only the sound of cigarette lighter being heard, or the breathing, coughing, or smoking of the two men that we never actually see.

Porumboiu refuses all the conventions of cinematic off-screen. Even the classical off-screen storyteller, the all-knowing "Voice" of the narrator which creates the coherence of the plot is transformed. In this father-son dialogue there are no cues for who is conducting the discussion, everything is taking place in a confusion of media. Also there are no gaze directions, and the absence of the off-screen gaze, which in classical films allows the spectator to orientate within the visual is missing. Also the "real-time" sensation of the televised program is substituted with the real-time of the dialogue, thus the simultaneous projection of two separate timelines generates the a mixed timeline, which is quintessentially extramedial. Actually there is no longer a cinematic time in this experimental production, since the father and son are constantly moving from one time frame to another. The "live television" is broken internally, once the nature of visibility is contested, since there is no transparency in the broadcast we see. Not only cinema, but also television as a medium is deprived of its specific traits - notwithstanding the indirect exposure of the role played by the Communist propaganda machine in the altering of reality.

“Doesn't this game look like one of my movies?", Corneliu Porumboiu asks his father bemusedly, "it is long and nothing happens". "You are not going to make a film out of this", his father reacts. Clearly the son did not listen to his father since $A l$ doilea joc was projected in cinemas all over the world, marking Porumboiu's effort to show the unshown, to hide the visible in order to make things explicit, to contradict the rules of cinema in order to create cinematic experiences. 


\section{The meaningless meaning and the de-dramatization of cinema}

A final argument is that Corneliu Porumboiu's movies are part of a process of de-dramatization of cinema, in turn part of a more important process of decinematization. This is obvious, for example in Al doilea joc, where Porumboiu uses the total refusal of any theatrical interventions - there are no actors, no entering or exiting the scene (in fact there is no scene!). Metabolism follows the same logic, more than half of the movie is built around only two characters, who most of the time not even visible. In this film there are no camera movements in the first six scenes, and the first movement happens only when a third person enters the visual field, disturbing the relationship between the director and his actress lover.

This is the case with other movies made by Porumboiu, and as a matter of fact it is a trait of the Nouvelle Vague, with Truffaut being one of the most relevant examples for how de-dramatized narratives operate. Another illustration can be Police, adjective - here the non-dramatic is amplified by apparent absence of activity of the main character (also shot for long time in a solitary pose, lacking any tension). This process is part of what I called "the abstinent Romanian cinema", a term that I used to describe the New Wave stylistics in the national film-making (see Pop 2014 6566). While an abstinent cinema is reduced in intensity and refuses all overtones - as opposed to the unclear and pejorative definition of "minimalist" - the non-dramatic cinema has an added function. It can be described as a type of moviemaking that is not simply refusing tension, but is also a reaction against the typical dramaturgy of the specific genres. Once more Police, adjective, which shows the traits of the abstinent moviemaking, can be an example for a de-dramatized cinematic narrative. This is a movie about a policeman that totally contradicts the genre of the policier. All the stereotypes of the police movies are negated, starting with the fact that an "action film" is transformed into a series of in-actions, an accumulation of absences, of nonactivities. Even the most important element in the genre, the final arrest, is missing and is place in the extra-cinematic.

Yet with his most recent film Porumboiu takes the device of de-genreification of storytelling at another level, at more complex and conceptual stage. Just as in Polițist, adjectiv he used the "policier" format only to create a anti-police movie about a policeman who does no policing, in Comoara he takes the trope of "treasure hunt", and explores its limitations. The treasure hunt remains one of the most widely used narrative devices, manifested from literature (the prose of Robert Louis Stevenson or H. Rider Haggard) to in-numerable movies (from the Indiana Jones series to National Treasure). The making of Comoara in a film environment where movies like The Pirates of the Caribbean: On Strager Tides was the most viewed production 2011 in Romania, reaching over 346.000 viewers, while Porumboiu's masterpiece (Polițist, adjectiv) had a total of only 12.000 viewers is a personal reaction of the director. 
Although Comoara remains within the logic of the "slice of life" cinema, using a story inspired by actual events (apparently it is a private family story of one of the actors, Adrian Purcărescu, whose grandfather buried his economies in the backyard of his home) and employing the New Wave "trademark" of long shots and slow paced sequences, the aim of the movie more complex. At a superficial glance, the movie is about two men, helped by a third one, to search for a treasure in the backyard of an old, abandoned house. One could say that Porumboiu even reuses his own visual stereotypes, since almost all his feature films are built around a group of three main characters, be it the professor, the pensioner and the producer in A fost sau n-a fost, or the three policemen in his 2009 masterpiece, Polițist, adjectiv.

Once again, we must underline the construction of a multi-layered, intertextual reference system in this overtly minimalist production. These references are linking the movie with the classical treasure hunt movies and novels, including the gangster genres, but also to the director's own works and the inner mechanisms of cinema. Here the de-dramatization does not mean a radical rejection of any narrative structure, as proposed by the "pure cinema" tradition. Once again, Porumboiu uses a film which is devoid of dramaturgical elements only as a means for exploring and understanding the profound nature of cinema. By contesting this canonic view of cinema as fundamentally a narration form, one that has its roots in the melodramatic narratives of early XIXth Century, the director is making a statement about cinematic art.

Most of the actions in Comoara are repetitive searches for a treasure that, although visible on the screen of the scanner, in not reachable. The two neighbors and their scanning specialist are ready to give up, after spending all daylight to find the treasure hidden in the backyard of an old manor. It is only at the end (I must advise for spoiler alert!) their efforts are turned into reality. Thy find a box, which is filled with old Mercedes bonds. This twist of fate, that brings their search to fruition without fulfilling their desire leads Costi to a radical gesture. In order not to disappoint his son, whom he promised a "real treasure", he sells the bonds and buys a treasure chests, which he fills with gold and diamonds.

Comoara deals with the content formation in movies and in art, and Porumboiu brilliantly builds up two distinct moments - both which describe the ambivalent nature of our existence and the nature of artistic representation. On one hand there is the utter platitude of reality. In the first part we follow the main hero, Costi, leading an unremarkable life, going to work, reading in the evening to his son from a Robin Hood booklet. What is the relationship between the dullness of the ordinary and the illusory manifestation of the fictionality? It is here that the other major function of de-dramatization intervenes. Once all dramaturgical elements (characters, conflicts, plots) are devoid of their functions, it is only then that the emotional impact can take a hold on us.

In the end what is cinema but the search for something that is not present, the quest for a reality that nobody believes anymore and of a materiality that, once found, is no 
longer what you expected it to be? The search for treasures is the search for meanings, for something that is NOT in the visual field, something requiring many efforts, and one that does not always present itself in the material manifestation that we expect. It is only after exhaustive search and digging for the "treasure", the three men were able to find something.

At the symbolic level, it deals with the capacity of Porumboiu as a director to extract meanings from his own cinematic work only after exhausting all the possible resource. It is then and only then that he could change the dullness into attractiveness.

\section{Conclusion}

The arguments presented here support the idea that there is a non-cinematic stylistics developed by Corneliu Porumboiu in his last three films, which makes this director part of the long standing tradition of European non-cinematic practices. While Porumboiu is questioning the nature of his own inner world he also puts under scrutiny our imagination, the materiality of cinema, the mechanisms of fictions, the ontology of the celluloid or the reality of television, exploring the limits of the capacity of cinema to extract and generate meanings.

\section{Works Cited}

Ádám, Gyorgy (ed.) Visceral perception. Understanding Internal Cognition. New York: Springer, 1998.

Arnheim, Rudolf. Film as Art. Berkeley: University of California Press, 1957.

Aumont, Jacques, Alain Bergala, Michel Marie, Marc Vernet. L'Esthetique du film. Paris: Nathan, 1983.

Barattoni, Luca. Italian Post-Neorealist Cinema. Edinburgh: Edinburgh University Press, 2012. Barthes, Roland. Mythologies. Essais. Paris: Editions du Seuil, 1957.

Barthes, Roland. Empire of Signs, New York: Hill and Wang, 1983.

Bernard, Sheila Curran. Archival storytelling: a filmmaker's guide to finding, using, and licensing third-party visuals and music, New York: Macmillan, 2009

Bordwell, David, Janet Staiger and Kristin Thompson. Classical Hollywood Cinema. Film Style and Mode of Production to 1960, Taylor and Francis e-Library 2005, first edition Columbia University Press, 1985.

Bordwell, David. Planet Hong Kong. Harvard University Press, 2000.

Burch, Noël. Theory of Film Practice. Translated by Helen Lane, Princeton: Princeton University Press, 1981.

Cabañas, Kaira M. Off-Screen Cinema. Isidore Isou and the Lettrist Avant-Garde. Chicago: University Of Chicago Press, 2015

Cameron, Oliver G. Visceral sensory neuroscience : interoception. Oxford: Oxford University Press, 2002.

Deaca, Mircea. Cinematograful postfilmic. Note și lecturi despre filmul contemporan. Timișoara: Brumar, 2013. 
Derrida, Jaques. The Truth in Painting. Chicago: University of Chicago Press, 1987.

Eisenstein, Sergei. "Montage 1937," in Eisenstein, Sergei Selected Works, vol. 2, Towards a Theory of Montage, ed. Michael Glenny and Richard Taylor, London: British Film Institute, 1991.

Elleström, Lars. Media Borders, Multimodality and Intermediality. London: Palgrave Macmillan, 2010.

Furze, Robert. The Visceral Screen: Between the Cinemas of John Cassavetes and David Cronenberg. Bristol: Intellect, 2015.

Gauthier. Guy. Vingt leçons sur l'image et le sens. Paris: Edilig, 1982.

Hockley, Luke. Somatic Cinema: The relationship between body and screen - a Jungian perspective. New York: Routledge, 2014.

Jihoon, Kim, Between Film, Video, and the Digital: Hybrid Moving Images in the Post-Media Age. New York: Bloomsbury, 2016.

Merleau-Ponty, Marcel. The Visible and the Invisible: Followed by Working Notes. Evanston: Northwestern University Press, 1968.

Pop, Doru. Romanian New Wave Cinema: An Introduction. Jefferson: McFarland, 2014.

Rivette, Jacques. 'De l'Abjection' in Cahiers du Cinéma 120, June 1961.

Smith, Greg M. Film structure and the emotion system. Cambridge: Cambridge University Press, 2003.

Stewart, Garrett. Framed Time: Toward a Postfilmic Cinema (Cinema and Modernity Series). Chicago: University Of Chicago Press, 2007.

Willis, Holly. New Digital Cinema: Reinventing the Moving Image. London: Wallflower, 2005.

\section{Online references}

Porumboiu, Corneliu. press conference 2013, quoted by Mediafax, http://www.media fax.ro/cultura-media/corneliu-porumboiu-despre-metabolism-am-realizat-filmulcu-un-soi-de-nostalgie-pentru-pelicula-11353000.

Ancheta domnului Porumboiu, interview by Lavinia Gliga, DoR 16, 2014, http://www.deca torevista.ro/porumboiu-dor16/.

Totok, William. 'Trivialitatea vandabila', Radio France International Romania, February 2014, http://www.rfi.ro/cultur-61970-trivialitatea-vandabil.

Weissberg, Jay. Locarno Film Review: 'When Evening Falls on Bucharest or Metabolism', Variety, August 13, 2013. http://variety.com/2013/film/global/when-evening-falls-on-bu charest-or-metabolism-review-locarno-film-festival-1200577482/. 